(2) OPEN ACCESS

\title{
Unlocking the secrets of long non-coding RNAs in asthma
}

\author{
Fien Gysens $\odot,{ }^{1}$ Pieter Mestdagh, ${ }^{1}$ Eric de Bony de Lavergne, ${ }^{1}$ Tania Maes $\odot^{2}$
}

\begin{abstract}
- Additional supplemental material is published online only. To view, please visit the journal online (http://dx.doi. org/10.1136/thoraxjnl-2021 218359).
\end{abstract}

'OncoRNALab, Department of Biomolecular Medicine, Ghent University, Ghent, Belgium ${ }^{2}$ Laboratory for Translational Research in Obstructive Pulmonary Diseases, Department of Respiratory Medicine, Ghent University Hospital, Ghent, Belgium

\section{Correspondence to}

Dr Tania Maes, Laboratory for Translational Research in Obstructive Pulmonary Diseases, Department of Respiratory Medicine, Ghent University Hospital, Ghent, Belgium; tania.maes@ugent.be

Received 14 October 2021 Accepted 21 January 2022

\section{Check for updates}

(C) Author(s) (or their employer(s)) 2022. Re-use permitted under CC BY-NC. No commercial re-use. See rights and permissions. Published by BMJ.

\section{To cite: Gysens F,} Mestdagh P, de Bony de Lavergne $\mathrm{E}$, et al. Thorax Epub ahead of print: [please include Day Month Year]. doi:10.1136/

thoraxinl-2021-218359

\section{ABSTRACT}

Asthma is a very heterozygous disease, divided in subtypes, such as eosinophilic and neutrophilic asthma. Phenotyping and endotyping of patients, especially patients with severe asthma who are refractory to standard treatment, are crucial in asthma management and are based on a combination of clinical and biological features. Nevertheless, the quest remains to find better biomarkers that distinguish asthma subtypes in a more clear and objective manner and to find new therapeutic targets to treat people with therapy-resistant asthma. In the past, research to identify asthma subtypes mainly focused on expression profiles of protein-coding genes. However, advances in RNA-sequencing technologies and the discovery of non-coding RNAs as important posttranscriptional regulators have provided an entire new field of research opportunities in asthma. This review focusses on long non-coding RNAs (IncRNAs) in asthma; these are non-coding RNAs with a length of more than 200 nucleotides. Many IncRNAs are differentially expressed in asthma, and several have been associated with asthma severity or inflammatory phenotype. Moreover, in vivo and in vitro functional studies have identified the mechanisms of action of specific IncRNAs. Although IncRNAs remain not widely studied in asthma, the current studies show the potential of IncRNAs as biomarkers and therapeutic targets as well as the need for further research.

\section{INTRODUCTION}

Almost 340 million people worldwide suffer from asthma. Cases are found with a higher frequency in Western and more industrialised countries, where up to $10 \%$ of the population has asthma. ${ }^{1}$ Asthma is not one well-defined disease. Asthma symptoms include wheezing, chest tightness, coughing, shortness of breath and airflow limitation. These symptoms can change over time and do not affect all patients with similar intensity or frequency. This is due to both genetic and environmental factors which influence the pathogenic alterations within the airways, such as inflammation, airway remodelling, mucous hypersecretion, airway hyperresponsiveness and reversible airway obstruction. To describe the heterogeneity of asthma, several subtypes are defined. While multiple classification systems exist, the subtypes defined by Wenzel were mostly used in the studies discussed further. ${ }^{2}$ According to Wenzel, there are six different forms of asthma : (1) early-onset allergic Th2, (2) late-onset eosinophilic, (3) exercise-induced, (4) obesity-related, (5) neutrophilic and (6) paucigranulocytic asthma. Cases are sorted into the neutrophilic, eosinophilic and paucigranulocytic groups according to the percentage of inflammatory cells present in the airways. Although neutrophils represent the largest fraction of inflammatory cells in the airways, patients are categorised as having eosinophilic asthma if their sputum contains more than $3 \%$ eosinophils. Neutrophilic asthma is defined by more than $61 \%$ neutrophils in sputum and paucigranulocytic asthma by less than $3 \%$ eosinophils and less than $61 \%$ neutrophils in sputum. ${ }^{3}$ Still, these cut-offs-especially those for neutrophils-can differ among different research groups and geographical locations. The different asthma categories have now been further defined based on the underlying biology thanks to the advances in molecular techniques. Nevertheless, treatment response can overlap and a need for biomarkers to distinguish these subtypes in a more objective and practical manner remains. ${ }^{2}$

The immunological mechanisms in asthma are best understood for early-onset allergic asthma, where allergen exposure in susceptible individuals induces the initiation of a Th2 response, in which type 2 cytokines interleukin (IL)-4, IL-13 and IL-5 induce IgE production and activation of mast cells, recruitment of eosinophils, formation of mucusproducing goblet cells and thickening of the airway smooth muscle cells (ASMCs). ${ }^{45}$ These type 2 cytokines can also be produced by innate lymphoid cells type 2, which are considered to be important in late onset-eosinophilic asthma. ${ }^{5}$ In neutrophilic asthma, other pathways are thought to be of importance, including the induction of Th1 and Th17 responses. $^{24}$

Standard-of-care treatment for asthma consists of inhaled corticosteroids (ICS). Administration of corticosteroids results in the suppression of proinflammatory gene expression, inactivation of Th2 cells, mast cells and eosinophils, and an increase of anti-inflammatory gene expression as well as activation of regulatory $\mathrm{T}$ cells (Tregs). ${ }^{67}$ However, ICS are less efficient to control severe asthma and-when taken chronically-can lead to serious side effects, such as osteoporosis, diabetes and reduced growth velocity. ${ }^{8}$ Other treatments include long-acting inhaled $\beta 2$ agonists, low-dose theophylline, antileukotrienes and-for severe asthma-also biologicals. While all of these agents can bring substantial relief to patients, none of them are curative, and some patients appear to be insensitive to these and similar medicines. ${ }^{79}$ Despite the successes of type 2-targeting biologicals to treat severe eosinophilic asthma, there remains an unmet need for additional therapeutic options covering the range of patient-specific requirements, particularly for severe ICS-resistant patients with asthma. A crucial step to achieve such precision 


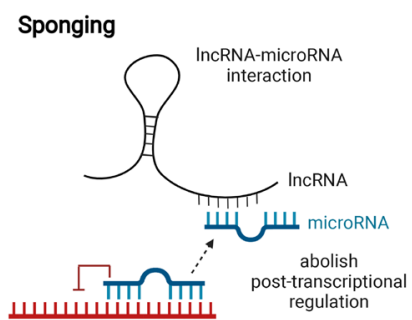

Scaffold

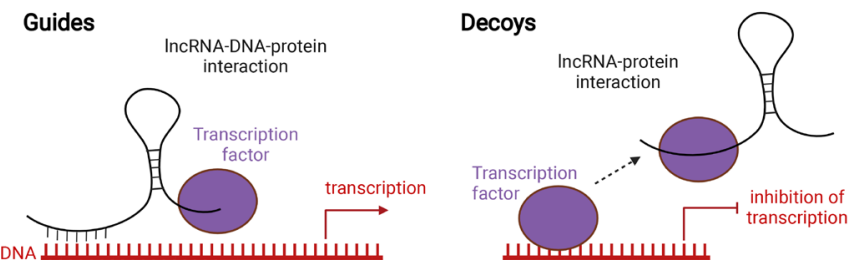

Figure 1 Main proposed working mechanisms of IncRNAs. IncRNAs can act as a sponge for microRNAs. By binding to these microRNAs, they prevent microRNAs from binding to their targets, thereby abolishing post-transcriptional regulation (top left). IncRNAs can act as scaffolds to facilitate the assembly of chromatin remodelling complexes and subsequent transcription (top right). IncRNAs can guide transcription factors to specific locations on the genome, thus facilitating transcription (bottom left). IncRNAs can act as a decoy by binding to transcription factors, thus leading to transcriptional repression (bottom right). Created with BioRender.com. IncRNA, long non-coding RNA.

medicine is the discovery of accurate biomarkers to distinguish different disease phenotypes and to determine optimal therapy (predictive biomarker) or predict the risk of future exacerbations (prognostic biomarker). Thus far, most biomarker studies have focused on protein-coding genes. However, the potential of noncoding RNAs as new biomarkers remains underexplored. ${ }^{10-15}$

The advances of RNA-sequencing technology revealed that our genome is pervasively transcribed producing thousands of coding and non-coding RNA molecules (ncRNAs). ncRNAs are transcribed, but not translated into proteins. ${ }^{16}$ There are different subtypes of ncRNAs, including microRNAs, ribosomal RNAs and transfer RNAs. In this review, we will focus on long non-coding RNAs (lncRNAs), as the role of microRNAs in asthma has been extensively studied and reviewed. ${ }^{17-20} \operatorname{lncRNAs}$ are arbitrarily defined by their length, over 200 nucleotides, and are emerging as regulators of various cellular processes, making them possible biomarkers and therapeutic targets. ${ }^{21}$ The origin of lncRNAs is not always known. Some are conserved among species; others are derived from protein-coding genes as a result of frame disruptions, chromosome rearrangements, duplication of another non-coding gene by retrotransposition, tandem duplication or insertion of a transposable element. ${ }^{22}$ Although IncRNAs generally have a low sequence conservation, their structure, splicing pattern and subcellular localisation are often conserved. ${ }^{23}$ IncRNAs can function through a variety of mechanisms and are defined into several functional subtypes, among which the sponges, scaffolds, guides and decoys are among the most reported ones (figure 1$)^{24-27}$. Sponging lncRNAs can bind to microRNAs, thus preventing these microRNAs, which control post-transcriptional processes, to interact with their targets. IncRNAs can also facilitate the formation of chromatin remodelling complexes and subsequent gene transcription (scaffold). IncRNAs can function as guides to lead a transcription factor to a specific DNA location to regulate transcription. As decoys, IncRNAs can bind a transcription factor, preventing it from binding to DNA (figure 1). The potential involvement of $\operatorname{lncRNAs}$ in the pathogenesis of several diseases has been reported. ${ }^{28-31}$

This review discusses the status of lncRNA research in asthma and defines the next steps required to evaluate their potential as new biomarkers or therapeutic targets. PubMed was searched using the query "IncRNAs" AND "asthma". Articles regarding lncRNA discovery in asthma as well as in vitro and in vivo functional studies published since 2012 were included.

\section{IDENTIFYING LNCRNAS IN ASTHMA}

To identify asthma-associated lncRNAs, gene expression profiling technologies, such as RNA-sequencing or microarrays, are typically used. There are multiple relevant cell types in asthma, such as immune cells and respiratory epithelial cells, which can be either sampled in blood, sputum or by bronchial brushings. The following paragraphs discuss human studies where lncRNA expression in samples from patients with asthma and healthy individuals were compared. Significant differential $\operatorname{lncRNAs}$ are typically selected based on a statistical test and resulting $\mathrm{p}$ value or false discovery rate (FDR). Also the fold change (FC), which shows the extent of differential expression, is often used. Sample size and applied cut-off values (both for $\mathrm{p}$ value, FDR and $\mathrm{FC}$ ) will affect the number of identified differentially expressed lncRNAs. Since many discovery studies are underpowered, with small sample sizes (table 1), we focused on those that found lncRNAs with functions that can contribute to asthma pathogenesis. The differences in technical approaches and cut-off values, sample type and size and asthma heterogeneity are important to keep in mind when comparing results between studies.

\section{IncRNAs in T cells}

$\mathrm{CD}^{+} \mathrm{T}$ cells drive the inflammatory and allergic responses in allergic asthma. Three independent studies have profiled lncRNA expression in $\mathrm{CD}^{+} \mathrm{T}$ cells in human peripheral blood $\mathrm{T}$ cells. ${ }^{32-34}$ Notably, the number of differentially expressed lncRNAs between $\mathrm{CD} 4^{+} \mathrm{T}$ cells from asthma samples and healthy controls differs strongly between different studies, ranging from 6 to over 2000 (table 1). Although differential lncRNA expression is confirmed by reverse transcription quantitative PCR (RTPCR) within specific studies, there is unfortunately no overlap in the reported lncRNAs from the different studies, which may be due to differences in asthma phenotype, source of the $\mathrm{T}$ cells, sample number and used technologies, ${ }^{32-35}$ as well as the difficulty to evaluate overlap due to annotation discrepancies.

Still, some studies linked the identified lncRNAs to asthma severity or pathogenesis. Tsitsiou et al, for example, did find not only 6 differentially expressed lncRNAs in $\mathrm{CD}^{+} \mathrm{T}$ cells but also 167 differentially expressed lncRNAs in $\mathrm{CD} 8^{+} \mathrm{T}$ cells in patients with severe asthma $(\mathrm{n}=12)$ compared with healthy controls $(\mathrm{n}=8) .{ }^{32}$ Moreover, these $\mathrm{CD} 8^{+} \mathrm{T}$ cells, but not $\mathrm{CD} 4^{+}$ $\mathrm{T}$ cells, were activated in severe asthma, suggesting an involvement of lncRNAs in $\mathrm{CD} 8^{+}$T-cell activation in severe asthma. ${ }^{32}$ This novel concept requires further validation.

In a large study, Qiu et al identified 225 differentially expressed lncRNAs in $\mathrm{CD}^{+} \mathrm{T}$ cells from severe asthma $(\mathrm{n}=52)$ compared with controls $(\mathrm{n}=45),{ }^{34}$ and demonstrated that the lncRNA MEG3 plays a role in Treg/Th17 balance, which has been linked to allergic asthma before. ${ }^{36}$

The functional role of MEG3 and other identified lncRNAs (eg, MALAT-1 and CACS7) ${ }^{34}$ will be further discussed in the next section. 
Table 1 Summary of human studies with gene expression profile data in asthma focusing on IncRNAs

\begin{tabular}{|c|c|c|c|c|c|c|}
\hline & Study & Technology & Sample type & $\begin{array}{l}\text { Candidate/identified } \\
\text { IncRNAs }\end{array}$ & Upregulated IncRNAs (n) & $\begin{array}{l}\text { Downregulated IncRNAs } \\
\text { (n) }\end{array}$ \\
\hline \multicolumn{7}{|l|}{$\mathrm{T}$ cells } \\
\hline & \multirow[t]{2}{*}{ Tsitsiou et $a l^{\beta 2}$} & \multirow[t]{2}{*}{ Microarray } & $\begin{array}{l}\text { Human } C D 4^{+} T \text { cells from circulating blood } \\
\text { Severe asthma }(n=12) \text {, healthy subjects } \\
(n=8)\end{array}$ & AC090517.2 & $\begin{array}{l}\text { Severe asthma versus } \\
\text { healthy: } 0\end{array}$ & $\begin{array}{l}\text { Severe asthma versus } \\
\text { healthy: } 6\end{array}$ \\
\hline & & & $\begin{array}{l}\text { Human } C D 8^{+} T \text { cells from circulating blood } \\
\text { Severe asthma }(n=12) \text {, healthy subjects } \\
(n=8)\end{array}$ & MEG3, SNHG3, FBLL1, GHRLOS & $\begin{array}{l}\text { Severe asthma versus } \\
\text { healthy: } 141\end{array}$ & $\begin{array}{l}\text { Severe asthma versus } \\
\text { healthy: } 26\end{array}$ \\
\hline & Qi et $a l^{33}$ & Microarray & $\begin{array}{l}\text { Human } \mathrm{CD}^{+} T \text { cells from circulating blood } \\
\text { Asthma }(n=5) \text {, healthy subjects }(n=5)\end{array}$ & Inc-NOS2-1, Inc-FAM222B-1 & Asthma versus control: 863 & Asthma versus control: 1862 \\
\hline & Qiu et $a l^{34}$ & Microarray & $\begin{array}{l}\text { Human } C D 4^{+} T \text { cells from circulating blood } \\
\text { Severe asthma }(n=52) \text {, healthy subjects } \\
(n=45)\end{array}$ & $\begin{array}{l}\text { MALAT1, MEG3, GAS5, NEAT1, } \\
\text { DANCR, HULC, FTLP3, KCNA3, } \\
\text { CACS7 }\end{array}$ & $\begin{array}{l}\text { Severe asthma versus } \\
\text { healthy: } 112\end{array}$ & $\begin{array}{l}\text { Severe asthma versus } \\
\text { healthy: } 113\end{array}$ \\
\hline \multicolumn{7}{|l|}{ Blood } \\
\hline & Chen et $a P^{37}$ & $\begin{array}{l}\text { Next-generation } \\
\text { sequencing }\end{array}$ & $\begin{array}{l}\text { Human whole blood severe asthma }(n=3) \text {, } \\
\text { mild asthma }(n=3) \text { healthy subjects }(n=3)\end{array}$ & $\begin{array}{l}\text { RP5-857K21.7, RP11-58A11.2, } \\
\text { Inc-TRAP1-1 }\end{array}$ & $\begin{array}{l}\text { Mild versus normal: } 20 \\
\text { Severe versus normal: } 504 \\
\text { Severe versus mild: } 50\end{array}$ & $\begin{array}{l}\text { Mild versus normal: } 76 \\
\text { Severe versus normal: } 104 \\
\text { Severe versus mild: } 93\end{array}$ \\
\hline & Zhu et $\left.a\right|^{\beta 9}$ & $\begin{array}{l}\text { Next-generation } \\
\text { sequencing }\end{array}$ & $\begin{array}{l}\text { Human whole blood } \\
\text { Eosinophilic asthma ( } n=9 \text { of which } n=6 \text { had } \\
\text { high lgE and } n: 3 \text { had low lgE) and control } \\
\text { subjects ( } n=3 \text { ) }\end{array}$ & $\begin{array}{l}\text { HNRNPU-AS1, RP11-401.2, } \\
\text { RP5-998N21.4, XLOC_000953, } \\
\text { OIP5-AS1, SCARNA10, } \\
\text { XLOC_011115 }\end{array}$ & Asthma versus control: 27 & Asthma versus control: 14 \\
\hline & Zhu et a/ ${ }^{38}$ & $\begin{array}{l}\text { Next-generation } \\
\text { sequencing }\end{array}$ & $\begin{array}{l}\text { Human whole blood } \\
\text { Neutrophilic asthma }(n=6) \text {, eosinophilic } \\
\text { asthma }(n=12) \text { and control subjects }(n=6)\end{array}$ & LNC_000127 & Asthma versus control: 117 & Asthma versus control: 178 \\
\hline \multicolumn{7}{|l|}{ Airways } \\
\hline & Liu et $a l^{40}$ & Microarray & $\begin{array}{l}\text { Human airway epithelial brushings } \\
\text { Asthma }(n=62) \text { and healthy controls }(n=43)\end{array}$ & $\begin{array}{l}\text { AC124067.4, ZNF667AS1, } \\
\text { AC005906.2, AL357568.2, } \\
\text { AC130650.2, STX18AS1, } \\
\text { LINC02363, LINC02145 }\end{array}$ & Asthma versus control: 48 & Asthma versus control: 111 \\
\hline & Austin et $a l^{41}$ & Microarray & $\begin{array}{l}\text { Human primary ASMCs } \\
\text { Non-severe asthma }(n=9) \text {, severe asthma } \\
(n=9) \text { and healthy controls }(n=9)\end{array}$ & $\begin{array}{l}\text { PVT1, LINC00472, RP5- } \\
\text { 1158E12.3, FKBP1A-SDCBP2 }\end{array}$ & $\begin{array}{l}\text { Non-severe versus control: } \\
15 \\
\text { Severe versus control: } 13\end{array}$ & $\begin{array}{l}\text { Non-severe versus control: } 6 \\
\text { Severe versus control: } 6\end{array}$ \\
\hline
\end{tabular}

A selection of IncRNAs of interest based on the focus of the article or literature is mentioned in the table.

ASMC, airway smooth muscle cell; IncRNA, long non-coding RNA.

\section{IncRNAs in blood}

Other studies focus on lncRNA expression in whole blood rather than individual cell types isolated from blood. ${ }^{37-39}$ Whole blood can be of interest to look for biomarkers, as there can be spillover of inflammatory processes from the lung into the blood, and it is easy to implement the sampling in the clinic. Nevertheless, whole blood also contains lncRNAs associated with the blood immunological profile as such, being not-related to asthma, as well as platelet-derived lncRNAs.

Zhu and colleagues investigated the lncRNA expression profiles in eosinophilic asthma. ${ }^{39}$ They found 41 differentially expressed IncRNAs in whole blood from eosinophilic asthma $(n=9)$ compared with controls $(n=3)$. Pathway analysis based on the coexpression of certain lncRNAs with certain messenger RNA (mRNAs) revealed that the 41 lncRNAs were mainly correlated to mRNAs involved in immune regulation. ${ }^{39}$ Moreover, these transcripts could be detected in peripheral blood, supporting their role as potential biomarkers, yet further work will be needed in larger and independent cohorts to confirm their diagnostic/prognostic value in eosinophilic asthma. The same research group subsequently investigated whether lncRNA expression differs between asthma inflammatory phenotypes and found 190 differentially expressed IncRNAs in eosinophilic asthma $(n=12)$ and 166 in neutrophilic asthma $(n=6)$ compared with healthy controls $(n=6)$. Notably, LNC_000127 was expressed higher in eosinophilic asthma compared with neutrophilic asthma and controls (more details are discussed in the online supplemental materials). ${ }^{38}$

\section{IncRNAs in airways}

Finally, the lncRNA expression landscape was also investigated in samples from the airways. Liu et al looked at publicly available datasets (NCBI Gene Expression Omnibus and GEO) from airway epithelial brushings from patients with asthma $(n=62)$ and controls $(n=43)$ and identified 159 differentially expressed IncRNAs between these two groups. ${ }^{40}$ The authors then selected eight lncRNAs that potentially interact with mRNAs, based on functional gene analysis through coexpression networks of lncRNAs and mRNAs. These eight lncRNAs were enriched in asthma-associated pathways such as airway remodelling and vascular endothelial growth. Experimental studies are required to validate interactions between these lncRNAs and mRNAs.

Austin et al used microarrays to look at differential lncRNA expression in ASMCs. Compared with healthy controls $(n=9)$, 21 lncRNAs were differentially expressed in non-severe asthma $(n=9)$ and 19 lncRNAs were differentially expressed in severe asthma $(n=9)$. Four of the lncRNAs were overlapping, including PVT1, which will be further discussed. ${ }^{41}$

Boudewijn et al performed RNA-sequencing on bronchial biopsies of patients with asthma who were in remission $(n=14)$ and patients with asthma with persistent asthma $(n=46)$. They found 35 lncRNAs that were linked with complete remission, yet no information on expression patterns was provided. ${ }^{42}$ Understanding the role of these lncRNAs may provide important insights into the disease trajectory of asthma.

In summary, the aforementioned studies all identified multiple lncRNAs exhibiting differential expression in asthma or specific 
asthma phenotypes, but few lncRNAs were replicated in different studies (table 1). This can probably be explained by the small sample cohorts in these studies and the huge difference in the origin of biological samples.

\section{FUNCTIONAL ROLE OF LNCRNAS IN ASTHMA}

The functional role of several specific lncRNAs, which were selected based on profiling studies (see above) or on previous knowledge in other diseases, was more thoroughly investigated in several studies. In the following paragraphs, we focus on specific lncRNAs that are either upregulated or downregulated in asthma and were functionally studied. We describe the in vitro and/or in vivo approaches that were used to obtain insights in lncRNA function. An overview of these lncRNAs, their expression in asthma, their interactions with miRNAs or proteins and their potential role in specific asthma-associated processes is given in table 2 and figure 2. Techniques to study interactions between lncRNAs and proteins or RNA are shown in figure 3 . These include luciferase reporter assays to visualise sponging of microRNAs and RNA pull-down experiments to detect proteins and RNAs that were bound to an RNA of interest. Also RNA immunoprecipitation helps to detect RNAs that bind to a protein of interest.

\section{Maternally expressed 3 (MEG3)}

Although MEG3 was identified as differentially expressed in several studies, the data are not univocal. In $\mathrm{CD}^{+}{ }^{+} \mathrm{T}$ cells of patients with severe asthma, MEG3 expression levels were upregulated and associated with reduced microRNA-17 expression. ${ }^{34}$ Silencing of MEG3 expression in $\mathrm{CD} 4^{+} \mathrm{T}$ cells by siRNA knockdown reduced the expression of Th17 transcription factor ROR $\gamma t$ and IL-17 and resulted in upregulation of microRNA-17. Luciferase reporter assays and RNA pull-down experiments (figure 3) demonstrated that MEG3 inhibits microRNA-17 by functioning as a competing RNA sponge. Moreover, microRNA-17 can suppress Th17 response by targeting RORyt, suggesting that MEG3 plays a role in the Th17 imbalance in asthma. ${ }^{34}$ Since elevated Th17 responses are linked to moderate and severe asthma, MEG3 could be a biomarker for asthma severity. ${ }^{43}$

In $\mathrm{CD} 8^{+} \mathrm{T}$ cells, on the other hand, MEG3 was found downregulated. ${ }^{32}$ This contradictory finding requires further research and validation, since $\mathrm{RORyt}^{+} \mathrm{CD} 8^{+} \mathrm{Tc} 17$ cells that produce IL-17 have been proposed to support Th17 responses in asthma. ${ }^{44}$ MEG3 was also downregulated in serum of patients with asthma compared with controls, especially in mixed eosinophilic/ neutrophilic asthma, and was negatively correlated with asthma progression. ${ }^{45}$ Possibly the different sample types and timing can influence the findings on MEG3 expression in asthma. ${ }^{3445}$

\section{LNC_00882}

lncRNAs can also affect airway smooth muscle function, which is important in asthma. ${ }^{46}$ The role of LNC_00882 was evaluated through gain-of-function and loss-of-function experiments in ASMCs. LNC_00882 was elevated in ASMCs treated with platelet-derived growth factor (PDGF) and promoted their proliferation. Luciferase reporter and RNA pull-down assays to discover the interaction partners of LNC 00882 revealed that LNC 00882 directly interacted with microRNA-3169-5p that can target $\beta$-catenin. Liu et al thus concluded that LNC_00882 promotes the proliferation of ASMCs by enhancing Wnt/ $\beta$-catenin signalling via sponging of microRNA-3619-5p, supporting a role for LNC_00882 in airway remodelling. ${ }^{46}$
Perry et al also observed upregulation of LNC_00882 in human ASMCs and that this IncRNA has seven sites that are complementary to microRNA-371. ${ }^{47}$ Notably, others reported that microRNA-371 (in cooperation with four other microRNAs) plays a role in the Th1/Th2 balance in asthma by inhibiting Runx3, a transcription factor that promotes Th1 diferentiation. ${ }^{48}$ It remains to be investigated whether LNC_00882 and/or microRNA-371 fulfil similar roles in ASMCs.

\section{Cancer susceptibility candidate 7 (CASC7)}

In ASMCs from patients with severe asthma, Liu et al discovered that CASC7 expression was suppressed ${ }^{49}$ and that it has a binding site for microRNA-21, a miRNA that is part of signalling pathway together with PTEN and AKT. Both microRNA-21 and AKT activity were upregulated in ASMCs from patients with severe asthma. Modulation of CASC7 and microRNA-21 expression and luciferase reporter assays demonstrated interactions between CASC7, microRNA-21 and PTEN mRNA. Overall, Liu et al concluded that CASC7 promotes PTEN expression through inhibiting microRNA-21 expression. Moreover, overexpression of CASC7 inhibited the PI3K/AKT pathway leading to increased corticosteroid sensitivity. ${ }^{49}$ Further in vivo experiments combining corticosteroids and CASC7 RNA could evaluate therapeutic potential. Of note, in $\mathrm{CD}^{+}{ }^{+} \mathrm{T}$ cells, an upregulated expression of CASC7 was reported. ${ }^{34}$ Since lncRNAs can have cell type-specific functions, these two studies are not necessarily contradictory.

\section{Metastasis-associated lung adenocarcinoma transcript 1 (MALAT1)}

Four studies observed higher expression of MALAT1 in asthma in human ASMCs induced by PDGF, ${ }^{50}$ in $\mathrm{CD}^{+} \mathrm{T}$ cells isolated from blood from patients with asthma, ${ }^{51}$ in ASMCs isolated from asthmatic rats ${ }^{52}$ and in newborn asthmatic rat models. ${ }^{53}$ In human ASMCs, siRNA-mediated knockdown of MALAT1 inhibited proliferation and migration. ${ }^{50}$ Luciferase reporter assays revealed a direct interaction between MALAT1 and microRNA-150. The translation initiation factor 4E (eIF4E), a key player in the AKT pathway, is a direct target of microRNA-150. As a result, MALAT1 can activate AKT signalling through sponging of microRNA-150, leading to proliferation and migration of ASMCs (airway remodelling). ${ }^{50}$ Another independent in vitro study in rat ASMCs associated MALAT1 levels and microRNA-216a to cell proliferation, migration and apoptosis, suggesting that the interaction of MALAT1 with several miRNAs has a role in airway remodelling. ${ }^{52}$ Knocking down MALAT1 in primary bronchial and tracheal smooth muscle cells also reduced apoptosis and proinflammatory cytokine production, with involvement of the microRNA-133a-ryanodine receptor-2 (RyR2) axis. ${ }^{53}$ Notably, RyR2 has been associated with childhood asthma. ${ }^{54}$

In human CD4 + T cells, Liang et al demonstrated using knockdown experiments and luciferase reporter assays that MALAT1 can also sponge the asthma associated microRNA- $155,{ }^{55}$ which affects the Th1/Th2 balance in asthma through a CTLA-4dependent mechanism. ${ }^{51}$

Overall, MALAT-1 appears to have multifaceted and cell-type specific functions, with involvement in both airway remodelling and the Th1/Th2 balance, supporting further investigations into MALAT1 as therapeutic target for asthma. ${ }^{5051}$ 
Table 2 IncRNAs and their possible interaction partners and effects, based on human and animal data

\begin{tabular}{|c|c|c|c|c|c|}
\hline IncRNAs & Cell type & $\begin{array}{l}\text { Proposed interaction } \\
\text { partners }\end{array}$ & $\begin{array}{l}\text { Impact on pathway or } \\
\text { transcription factor }\end{array}$ & Proposed effects & $\begin{array}{l}\text { Upregulated or } \\
\text { downregulated }\end{array}$ \\
\hline \multirow[t]{3}{*}{ MEG3 } & Human $\mathrm{CD}^{+} \mathrm{T}$ cells $\mathrm{s}^{32}$ & & & & \\
\hline & Human serum ${ }^{45}$ & & & Asthma progression ${ }^{45}$ & \\
\hline & Human $\mathrm{CD}^{+} \mathrm{T}$ cells ${ }^{34}$ & MicroRNA-17 $7^{34}$ & $\mathrm{ROR} \gamma \mathrm{T}^{34}$ & Th17 imbalance ${ }^{34}$ & \\
\hline LNC_000127 & Human whole blood ${ }^{38}$ & & $\mathrm{GATA}^{38}$ & Th2 inflammation ${ }^{38}$ & \\
\hline LNC_00882 & Human ASMCs ${ }^{46} 47$ & $\begin{array}{l}\text { MicroRNA-3169-5 } p^{46} \\
\text { MicroRNA-371 }\end{array}$ & $\begin{array}{l}\text { Wnt } / \beta \text {-catenin } \\
\text { Runx }^{46}\end{array}$ & $\begin{array}{l}\text { Airway remodelling }{ }^{46} \\
\text { Th1/Th2 imbalance }\end{array}$ & \\
\hline CACS7 & Human ASMCs ${ }^{49}$ & MicroRNA-21 ${ }^{49}$ & PTEN/AKT ${ }^{49}$ & Corticosteroid sensitivity ${ }^{49}$ & \\
\hline MALAT1 & $\begin{array}{l}\text { Human ASMCs }{ }^{50} \\
\text { Human CD4 } 4^{+} \text {cells }^{51} \\
\text { Rat ASMCs }\end{array}$ & $\begin{array}{l}\text { MicroRNA-150 } \\
\text { MicroRNA-155 } \\
\text { MicroRNA-261 } \\
\text { MicroRNA-133a } \\
\text { 53 }\end{array}$ & $\begin{array}{l}\mathrm{AKT}^{50} \\
\text { CTLA-4 }\end{array}$ & $\begin{array}{l}\text { Airway remodelling }{ }^{50} \\
\text { Th1/Th2 imbalance }\end{array}$ & \\
\hline TUG1 & $\begin{array}{l}\text { Rat ASMCs }{ }^{57} \\
\text { Mice ASMCs } \\
\text { Human monocytes }\end{array}$ & $\begin{array}{l}\text { MicroRNA-590-5 } p^{57} \\
\text { MicroRNA-181 } b^{58} \\
\text { MicroRNA-29 } c^{56}\end{array}$ & $N F-\kappa B^{58}$ & $\begin{array}{l}\text { Airway remodelling }^{57} \\
\text { Inflammation } \\
\text { Th2 cell differentiation }\end{array}$ & \\
\hline TCF7 & Human ASMCs ${ }^{78}$ & TIMMDC1 $^{78}$ & $\mathrm{AKT}^{81}$ & Airway remodelling ${ }^{78}$ & \\
\hline GAS5 & $\begin{array}{l}\text { Rat ASMCs } \\
\text { Human ASMCs } \\
\text { Human monocytes }\end{array}$ & MicroRNA-10 $a^{61}$ & BDNF $^{64}$ & $\begin{array}{l}\text { Airway hyper-responsiveness }{ }^{61} \\
\text { Glucocorticoid insensitivity } \\
\text { Severity }^{63}\end{array}$ & \\
\hline BCYRN1 & Rat $\mathrm{ASMCs}^{76}$ & $\mathrm{TRPC}^{76}$ & & Airway remodelling ${ }^{82}$ & \\
\hline \multirow[t]{4}{*}{ PVT1 } & Human ASMCs ${ }^{41}$ & & & Airway remodelling ${ }^{41}$ & \\
\hline & Rat $\mathrm{ASMCs}^{65}$ & MicroRNA-203a ${ }^{65}$ & $\mathrm{E} 2 \mathrm{~F} 3^{65}$ & $\begin{array}{l}\text { Reaction on } \alpha \text {-asarone and airway } \\
\text { remodelling }\end{array}$ & \\
\hline & $\begin{array}{l}\text { Mice ASMCs and CD4 }{ }^{+} \mathrm{T} \\
\text { cells }^{66}\end{array}$ & MicroRN29c-3p $p^{66}$ & $\mathrm{AKT} / \mathrm{mToR}{ }^{66}$ & & \\
\hline & $\begin{array}{l}\text { Human small airway } \\
\text { epithelial cells }{ }^{67}\end{array}$ & MicroRNA-14967 & & & \\
\hline NEAT1 & $\begin{array}{l}\text { Human leucocytes }^{68} \\
\text { Human plasma }^{11}\end{array}$ & MicroRNA-124 $4^{11}$ & & Exacerbation risk ${ }^{11}$ & \\
\hline ANRIL & Human plasma ${ }^{12}$ & MicroRNA-125a $a^{12}$ & & Exacerbation risk $^{12}$ & \\
\hline AK085865 & Asthma mice model ${ }^{77}$ & & & Inflammation ${ }^{77}$ & \\
\hline PINT & Rat $\mathrm{ASMCs}^{69}$ & MicroRNA-26a-5p ${ }^{69}$ & PTEN $^{69}$ & Inflammation ${ }^{69}$ & \\
\hline NKILA & Asthma mice model ${ }^{70}$ & & $N F-\kappa B^{70}$ & M2 macrophage polarisation ${ }^{70}$ & \\
\hline CRNDE & Human PBMCs ${ }^{71}$ & $\begin{array}{l}\text { MicroRNA-33a \& } \\
\text { MicroRNA-495 }\end{array}$ & & Exacerbation severity ${ }^{71}$ & \\
\hline n337374 & Asthma mice model ${ }^{72}$ & & & Inflammation ${ }^{72}$ & \\
\hline OIP5-AS1 & BEAS-2B cell line ${ }^{73}$ & MicroRNA-143-3 $p^{73}$ & $\mathrm{HMGB}^{73}$ & Inflammation and apoptosis ${ }^{73}$ & \\
\hline $\mathrm{H} 19$ & Human ASMCs ${ }^{74}$ & MicroRNA-21 ${ }^{74}$ & $\mathrm{AKT}^{74}$ & Airway remodelling ${ }^{74}$ & \\
\hline IncBAZ2B & Human PBMCs ${ }^{75}$ & & $B A Z 2 B^{75}$ & M2 macrophage activation ${ }^{75}$ & \\
\hline
\end{tabular}

ASMC, airway smooth muscle cell; IncRNA, long non-coding RNA; PBMC, peripheral blood mononuclear cell.

\section{Taurine upregulated 1 (TUG1)}

Sun et al observed that TUG1 is differentially expressed in monocytes of children with asthma. By performing in vitro experiments on macrophages, they demonstrated that TUG1 sponges microRNA-29c, which has been linked to Th2 cell differentiation. ${ }^{56}$

By using a rat model, Lin $e$ al studied the function of TUG1 in asthma. ${ }^{57}$ TUG1 was upregulated in the ASMCs of an asthma 


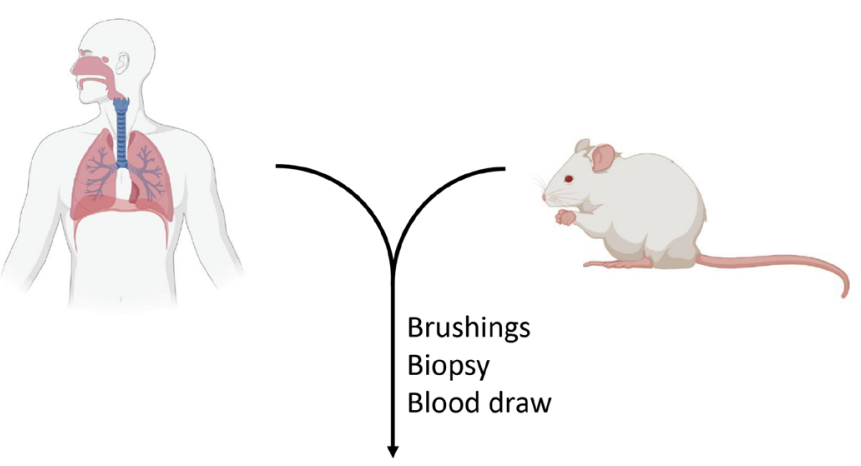

Isolation and/or purification

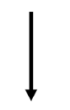

Determine IncRNA expression
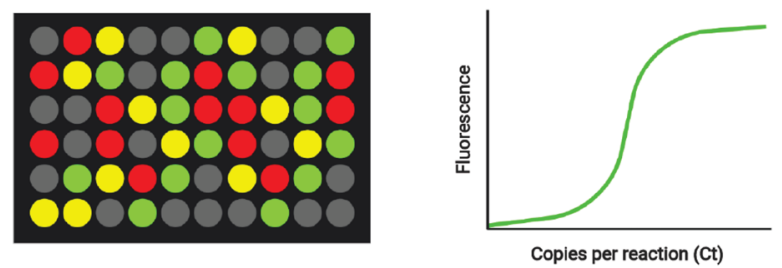

$\downarrow$

Functional examination in vitro or in vivo

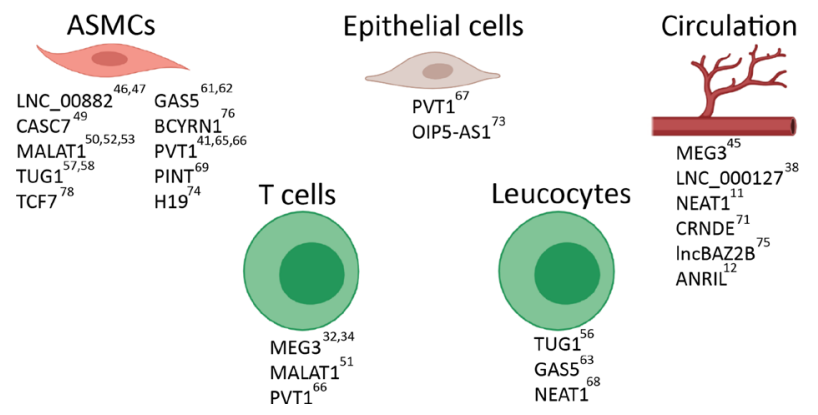

Figure 2 IncRNAs differenally expressed in asthma in human, rat or mice in different cell types. Created with BioRender.com. ASMC, airway smooth muscle cell; IncRNA, long non-coding RNA.

rat model compared with controls. In vitro silencing of TUG1 in these asthmatic ASMCs by siRNA led to impaired proliferation and migration and reduced fibroblast growth factor 1 (FGF1) expression. Further analysis demonstrated that TUG1 sponges microRNA-590-5p, which therefore no longer inhibits its target FGF1, thus favouring proliferation and migration of ASMCs (airway remodelling)..$^{57}$

In a study using asthmatic mice, Huang et al could link TUG1 to microRNA-181b. TUG1 acts as a sponge for microRNA$181 \mathrm{~b}$, which normally has a protective function in asthma, as it has anti-inflammatory properties. ${ }^{58}$ However, by sponging, TUG1 inhibits this function and activates the nuclear factor kappa-light-chain-enhancer of activated B cells (NF- $\mathrm{kB}$ ) signalling pathway and promotes airway remodelling. ${ }^{58}$ Two recent studies confirmed the involvement of TUG1 in ASMC proliferation in human asthma, by impacting on the miR216a-SMURF2 axis and the miR-138-E2F3 axis. $^{59} 60$
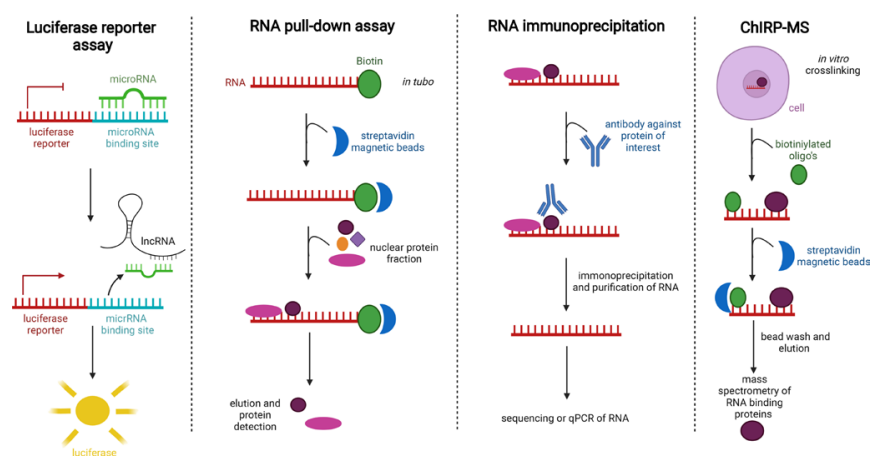

Figure 3 Different techniques to study protein-RNA and RNA-RNA interactions. With a luciferase reporter assay, sponging of a microRNA can be visualised. RNA pull-down enables us to extract proteins that bind to an RNA sequence of interest. RNA immunoprecipitation makes it possible to detect RNA that binds to a certain protein of interest. ChIRPMS enables us to perform mass spectrometry on proteins that bind to an RNA sequence of interest. IncRNA, long non-coding RNA.

\section{Growth arrest-specific 5 (GAS5)}

Multiple studies have looked at the possible function and potential of GAS5.$^{61-63}$ Wu et al found increased expression of GAS5 in peripheral blood of patients with severe and non-severe asthma compared with healthy controls. ${ }^{63}$ GAS5 expression reduced after treatment with dexamethasone, a synthetic glucocorticosteroid, in a mouse model of steroid-insensitive asthma. Keenan et al evaluated if GAS5 functioned as a decoy for the glucocorticoid receptor, playing an important role in glucocorticoid sensitivity. Instead of investigating GAS5 expression patterns in asthma, authors examined glucocorticoid sensitivity in vitro and observed that GAS5 can repress glucocorticoid receptor activity of ASMCs. ${ }^{62}$ Combining the data of Wu et al and Keenan et al, we found that GAS5 seems to promote glucocorticoid insensitivity. ${ }^{62} 63$

Zhang et al demonstrated that GAS5 expression levels in ASMCs from asthmatic rats are higher than in controls ${ }^{61}{ }^{11}$ Through RNA immunoprecipitation and RNA pull-down (figure 3), it was demonstrated that GAS5 acts as a sponge for microRNA-10a and that luciferase reporter assays subsequently showed an interaction between microRNA-10a and BDNF. This BNDF protein is produced by ASMCs and enhances inflammation and airway contractility. ${ }^{64}$ Elevated GAS5 expression promoted ASMC proliferation in vitro through the microRNA-10a/BDNF regulatory axis. Knockdown of GAS5 using siRNAs in vivo decreased airway hyper-responsiveness in asthmatic rats, indicating therapeutic potential. ${ }^{61}$

\section{Plasmacytoma variant translocation 1 (PVT1)}

Comparison of the lncRNA profile in ASMCs from healthy subjects, non-severe corticosteroid sensitive asthma and severe corticosteroid-insensitive asthma identified a number of differentially expressed lncRNAs, including PVT1, which is upregulated in corticosteroid-insensitive asthma. ${ }^{41}$ After in vitro treatment of these ASMCs with fetal calf serum (FCS) and dexamethasone, Austin et al saw that PVT1 expression was different in the ASMCs originating from the different groups. Whereas PVT1 expression reduced in ASMCs from non-severe asthma, it increased in ASMCs from corticosteroid-insensitive severe asthma and was unaffected in ASMCs from healthy subjects. ${ }^{41}$ Using siRNA targeting PVT1 in primary smooth muscle cells from patients with severe asthma, Austin et al further observed 
a decrease of IL-6 release and an increase in ASMC proliferation (airway remodelling). ${ }^{41}$

Yu et al used a rat model with respiratory syncytial virus (RSV) induced asthma and found PVT1 expression was higher in ASMCs. ${ }^{65}$ Treatment with $\alpha$-asarone, an anti-inflammatory and antioxidative component, resulted in reduced airway wall thickening in vivo and weakened cell viability, proliferation and migration capacity of ASMCs in vitro as well as a downregulation of the IncRNA PVT1 ${ }^{65}$ Short hairpins against PVT1 revealed its impact on cell viability, proliferation and migration capacity of ASMCs. Luciferase reporter assays showed that PVT1 acts as a sponge for microRNA-203a, which targets E2F3. Moreover, Yu et al demonstrated that this PVT1/miR-203/E2F3 pathway is affected by the $\alpha$-asarone treatment. To conclude, results suggest that PVT1 is a sponge for microRNA-203a, which regulates the expression of E2F3 in these asthmatic rats. ${ }^{65}$ However, further research is needed to investigate if similar mechanisms occur in humans with asthma.

Wei et al investigated the function of PVT1 in mice with ozone-triggered asthma. They could link high PVT1 expression levels to asthma and especially thicker ASMCs. In in vitro experiments, PVT sponges microRNA-29c-3p and therefore induces PI3K-Akt-mToR signalling. ${ }^{66}$

Ma et al also investigated the function of PVT1 showing that overexpression led to pathological development in human small airway epithelial cells. PVT1 was also seen to sponge microRNA-149. ${ }^{67}$

\section{Other IncRNAs}

More lncRNAs have been studied and found to be upregulated or downregulated in asthma or a certain asthma type. ${ }^{11} 123868-78$ A summary of these can be found in table 2, and a more extensive description of some of them can be found in supplemental materials. However, these IncRNAs were not extensively studied or described only in animals. As a result, more in vitro and in vivo experiments are needed to distinguish the exact function of these lncRNAs.

\section{CONCLUSION}

This review sheds light on IncRNA expression profiles in various cell types involved in the pathophysiology of asthma and their potential functional roles. Considering the heterogeneity of asthma and the published reports thus far, replication and validation studies on larger sample numbers from well-characterised patients are required to identify those IncRNAs that have a robust association with a specific asthma phenotype. The fact that differentially expressed lncRNAs can be detected in easily accessible samples such as plasma or serum underscores their potential to serve as biomarkers. ${ }^{11} 123845$ Nevertheless, more studies are required to identify those lncRNAs profiles that can identify a specific phenotype or can predict therapeutic response.

At this stage, most publications are descriptive and do not include functional experiments, with only a handful of lncRNAs that have been functionally investigated, such as MEG $3,{ }^{34}$ LNC_00882 $2^{46}$ and TUG1. ${ }^{57}$ There are thus multiple opportunities for further research.

Although lncRNAs can modulate gene expression in several ways (figure 1), most published functional studies in asthma focused on their capacity to sponge miRNAs. Further research is needed to investigate how the other lncRNA functionalities (decoys, guides and scaffolds) can have an impact on asthma and may present novel therapeutic opportunities. More multiomics approaches, combining genetics with lncRNA and miRNA expression data and proteomics, are needed to obtain insights into how genetics is linked to lncRNA and miRNA expression and how this impacts on protein expression in asthma. Little is known regarding the presence of lncRNAs in asthma genomewide association study (GWAS) hits. To our knowledge, only one recent GWAS study reported an lncRNA (CTD-253719.5) that colocalises with a locus linked to lung function. ${ }^{79}$ Also, the working mechanisms of lncRNAs, for example, the protein interaction partners of lncRNAs, should be investigated with relevant technologies, such as ChIRP-MS (comprehensive identification of RNA-binding proteins by mass spectrometry, a technique to discover proteins that bind to an RNA of interest, figure 3). ${ }^{80}$

Still, several of the identified lncRNA-associated pathways have an impact on asthma-associated pathogenic processes, such as Th1/Th2 balance, ${ }^{38474851}$ airway remodelling ${ }^{41} 46505765747678$ and insensitivity against certain drugs ${ }^{4962}$ suggesting that lncRNAs could become therapeutic targets. However, translation of these insights into the clinic will require major technical breakthroughs, such as approaches to modulate lncRNA function in specific cell types within the human lung.

To conclude, IncRNAs hold great potential as both biomarkers and therapeutic targets in asthma. However, this potential remains far from being fully evaluated, and more research is needed to precisely determine, characterise and exploit the most promising candidates. Nevertheless, these preliminary studies argue in favour of systematically integrating lncRNAs in asthma research.

Twitter Fien Gysens @Fien_G_

Contributors FG collected studies and wrote the review. EdBdL, PM and TM supervised literature review and writing. $\mathrm{EdBdL}$ and TM are joint last authors.

Funding The Department of Biomolecular Medicine is funded by a Concerted Research Action of Ghent University (BOF19-GOA-008). The Department of Respiratory Medicine is funded by a Concerted Research Action of Ghent University (BOF19-GOA-008) and Fund for Scientific Research in Flanders (FWO-EOS project G0G2318N)

Competing interests TM reports grants and personal fees from GlaxoSmithKline outside the submitted work, is a shareholder from Oryzon Genomics and Mendelion Lifesciences SL and holds a Chiesi chair on environmental factors in asthma.

Patient consent for publication Not applicable.

Ethics approval This study does not involve human participants.

Provenance and peer review Not commissioned; externally peer reviewed.

Open access This is an open access article distributed in accordance with the Creative Commons Attribution Non Commercial (CC BY-NC 4.0) license, which permits others to distribute, remix, adapt, build upon this work non-commercially, and license their derivative works on different terms, provided the original work is properly cited, appropriate credit is given, any changes made indicated, and the use is non-commercial. See: http://creativecommons.org/licenses/by-nc/4.0/.

\section{ORCID iDs}

Fien Gysens http://orcid.org/0000-0002-1515-311X

Tania Maes http://orcid.org/0000-0002-3037-6928

\section{REFERENCES}

1 The global asthma report, 2018. Available: http://www.globalasthmareport.org/ burden/burden.php

2 Wenzel SE. Asthma phenotypes: the evolution from clinical to molecular approaches. Nat Med 2012;18:716-25.

3 Syabbalo N. Clinical features and management of paucigranulocytic asthma. Ann Clin Med Res 2020:1:18.

4 Hammad H, Lambrecht BN. The basic immunology of asthma. Cell 2021;184:2521-2.

5 Brusselle GG, Maes T, Bracke KR. Eosinophils in the spotlight: eosinophilic airway inflammation in nonallergic asthma. Nat Med 2013;19:977-9.

6 Pelaia G, Vatrella A, Busceti MT, et al. Molecular and cellular mechanisms underlying the therapeutic effects of budesonide in asthma. Pulm Pharmacol Ther 2016;40:15-21.

7 Barnes PJ. Efficacy of inhaled corticosteroids in asthma. J Allergy Clin Immunol 1998; 102:531-8. 
8 Heffler E, Madeira LNG, Ferrando M, et al. Inhaled corticosteroids safety and adverse effects in patients with asthma. J Allergy Clin Immunol Pract 2018;6:776-81

9 Mukherjee M, Svenningsen S, Nair P. Glucocortiosteroid subsensitivity and asthma severity. Curr Opin Pulm Med 2017;23:78-88.

10 Strimbu K, Tavel JA. What are biomarkers? Curr Opin HIV AIDS 2010;5:463-6.

11 Li X, Ye S, Lu Y. Long non-coding RNA NEAT1 overexpression associates with increased exacerbation risk, severity, and inflammation, as well as decreased lung function through the interaction with microRNA-124 in asthma. J Clin Lab Anal 2020;34:e23023.

12 Ye S, Zhu S, Feng L. Lncrna ANRIL/miR-125a axis exhibits potential as a biomarker for disease exacerbation, severity, and inflammation in bronchial asthma. J Clin Lab Anal 2020:34:e23092.

13 Tiotiu A. Biomarkers in asthma: state of the art. Asthma Res Pract 2018;4:10.

14 di Palmo E, Cantarelli E, Catelli A, et al. The predictive role of biomarkers and genetics in childhood asthma exacerbations. Int J Mol Sci 2021;22:4651.

15 Gál Z, Gézsi A, Semsei Ágnes F, et al. Investigation of circulating IncRNAs as potential biomarkers in chronic respiratory diseases. J Trans/ Med 2020;18:422.

16 Strasser BJ. A world in one dimension: Linus Pauling, Francis Crick and the central dogma of molecular biology. Hist Philos Life Sci 2006;28:491-512.

17 Heffler E, Allegra A, Pioggia G, et al. Microrna profiling in asthma: potential biomarkers and therapeutic targets. Am J Respir Cell Mol Biol 2017;57:642-50.

18 Taka S, Tzani-Tzanopoulou P, Wanstall H, et al. Micrornas in asthma and respiratory infections: identifying common pathways. Allergy Asthma Immunol Res 2019;12:4-23.

19 Kho AT, McGeachie MJ, Moore KG, et al. Circulating microRNAs and prediction of asthma exacerbation in childhood asthma. Respir Res 2018;19:128.

20 Weidner J, Bartel S, Kılıç A, et al. Spotlight on microRNAs in allergy and asthma. Allergy 2021;76:1661-78.

21 Wahlestedt C. Targeting long non-coding RNA to therapeutically upregulate gene expression. Nat Rev Drug Discov 2013;12:433-46.

22 Ponting CP, Oliver PL, Reik W. Evolution and functions of long noncoding RNAs. Cell 2009;136:629-41.

23 Mercer TR, Dinger ME, Mattick JS. Long non-coding RNAs: insights into functions. Nat Rev Genet 2009;10:155-9.

24 Bayoumi AS, Sayed A, Broskova Z, et al. Crosstalk between long noncoding RNAs and microRNAs in health and disease. Int J Mol Sci 2016;17:356.

25 Marchese FP, Raimondi I, Huarte M. The multidimensional mechanisms of long noncoding RNA function. Genome Biol 2017:18:206.

26 Statello L, Guo C-J, Chen L-L, et al. Gene regulation by long non-coding RNAs and its biological functions. Nat Rev Mol Cell Biol 2021;22:96-118.

27 Li Z, Zhao W, Wang M. The role of long noncoding RNAs in gene expression regulation. Gene Expression Profiling in Cancer 2019.

28 Bink DI, Lozano-Vidal N, Boon RA. Long non-coding RNA in vascular disease and aging. Noncoding RNA 2019;5:26.

29 He J, Tu C, Liu Y. Role of IncRNAs in aging and age-related diseases. Aging Med 2018;1:158-75.

30 Zhang C, Ge S, Gong W, et al. Lncrna ANRIL acts as a modular scaffold of WDR5 and HDAC3 complexes and promotes alteration of the vascular smooth muscle cell phenotype. Cell Death Dis 2020;11:435.

31 Vencken SF, Greene CM, McKiernan PJ. Non-Coding RNA as lung disease biomarkers. Thorax 2015;70:501-3.

32 Tsitsiou E, Williams AE, Moschos SA, et al. Transcriptome analysis shows activation of circulating CD8+ T cells in patients with severe asthma. J Allergy Clin Immunol 2012;129:95-103.

33 Qi X, Chen H, Huang Z, et al. Aberrantly expressed IncRNAs identified by microarray analysis in $\mathrm{CD}^{+} \mathrm{T}$ cells in asthmatic patients. Biochem Biophys Res Commun 2018;503:1557-62.

34 Qiu Y-Y, Wu Y, Lin M-J, et al. LncRNA-MEG3 functions as a competing endogenous RNA to regulate Treg/Th17 balance in patients with asthma by targeting microRNA-17/ RORyt. Biomed Pharmacother 2019:111:386-94.

35 Wang Z, Ji N, Chen Z, et al. Next Generation Sequencing for Long Non-coding RNAs Profile for $\mathrm{CD}^{+} \mathrm{T}$ Cells in the Mouse Model of Acute Asthma. Front Genet 2019;10:545.

36 Zhao Y, Yang J, Gao Y-D, et al. Th17 immunity in patients with allergic asthma. Int Arch Allergy Immunol 2010;151:297-307.

37 Chen Y, Mao Z-D, Shi Y-J, et al. Comprehensive analysis of miRNA-mRNA-IncRNA networks in severe asthma. Epigenomics 2019;11:115-31.

38 Zhu Y, Mao D, Gao W, et al. Analysis of IncRNA expression in patients with eosinophilic and neutrophilic asthma focusing on LNC_000127. Front Genet 2019:10:141

39 Zhu Y-J, Mao D, Gao W, et al. Peripheral whole blood IncRNA expression analysis in patients with eosinophilic asthma. Medicine 2018;97:e9817

40 Liu $X$, Zhang $Y$, Jiang $H$, et al. Integrative analysis of the contribution of mRNAs and long non-coding RNAs to the pathogenesis of asthma. Mol Med Rep 2019:20:2617-24.

41 Austin PJ, Tsitsiou E, Boardman C, et al. Transcriptional profiling identifies the long noncoding RNA plasmacytoma variant translocation (PVT1) as a novel regulator of the asthmatic phenotype in human airway smooth muscle. J Allergy Clin Immunol 2017:139:780-9.

42 Boudewijn IM, Roffel MP, Vermeulen CJ, et al. A novel role for bronchial microRNAs and long noncoding RNAs in asthma remission. Am J Respir Crit Care Med 2020;202:614-8

43 Shi Y-heng, Shi G-chao, Wan H-ying, et al. Coexistence of Th1/Th2 and Th17/Treg imbalances in patients with allergic asthma. Chin Med J 2011;124:1951-6.

44 Li K, Wang Z, Cao Y, et al. The study of the ratio and distribution of Th17 cells and Tc17 cells in asthmatic patients and the mouse model. Asian Pac J Allergy Immunol 2013;31:125-31.

45 Feng Y, Yang C, Yan W. Expression of IncRNA MEG3 in asthma with different phenotypes and its relationship with course of disease. Exp Ther Med 2020;19:2211-7.

46 Liu Z, Mei L, He Z. Long non-coding RNA00882 contributes to platelet-derived growth factor-induced proliferation of human fetal airway smooth muscle cells by enhancing Wnt/ $\beta$-catenin signaling via sponging miR-3619-5p. Biochem Biophys Res Commun 2019;514:9-15.

47 Perry MM, Tsitsiou E, Austin PJ, et al. Role of non-coding RNAs in maintaining primary airway smooth muscle cells. Respir Res 2014;15:58.

48 Qiu Y-Y, Zhang Y-W, Qian X-F, et al. miR-371, miR-138, miR-544, miR-145, and miR214 could modulate Th1/Th2 balance in asthma through the combinatorial regulation of RUNX3. Am J Trans/ Res 2017:9:3184-99.

49 Liu J-H, Li C, Zhang C-H, et al. LnCRNA-CASC7 enhances corticosteroid sensitivity via inhibiting the PI3K/Akt signaling pathway by targeting miR-21 in severe asthma. Pulmonology 2020;26:18-26.

50 Lin L, Li Q, Hao W, et al. Upregulation of LncRNA Malat1 Induced Proliferation and Migration of Airway Smooth Muscle Cells via miR-150-elF4E/Akt Signaling. Front Physiol 2019;10:1337.

51 Liang Z, Tang F. The potency of IncRNA MALAT1/miR-155/CTLA4 axis in altering Th1/ Th2 balance of asthma. Biosci Rep 2020;40:BSR20190397.

52 Huang J, Wang FH, Wang L, et al. LncRNA MALAT1 promotes proliferation and migration of airway smooth muscle cells in asthma by downregulating microRNA216a. Saudi J Biol Sci 2021:28:4124-31.

53 Yang M, Wang L. Malat1 knockdown protects from bronchial/tracheal smooth muscle cell injury via regulation of microRNA-133a/ryanodine receptor 2 axis. J Biosci 2021;46:28

54 Ding L, Abebe T, Beyene J, et al. Rank-Based genome-wide analysis reveals the association of ryanodine receptor-2 gene variants with childhood asthma among human populations. Hum Genomics 2013:7:16.

55 Zhou H, Li J, Gao P, et al. miR-155: a novel target in allergic asthma. Int J Mol Sci 2016:17:1773.

56 Sun $\mathrm{H}$, Wang T, Zhang W, et al. LncRNATUG1 facilitates Th2 cell differentiation by targeting the miR-29c/B7-H3 axis on macrophages. Front Immunol 2021:12:2805.

57 Lin J, Feng X, Zhang J, et al. Long noncoding RNA TUG1 promotes airway smooth muscle cells proliferation and migration via sponging miR-590-5p/FGF1 in asthma. Am J Trans/ Res 2019:11:3159.

58 Huang W, Yu C, Liang S, et al. Long non-coding RNA TUG 1 promotes airway remodeling and mucus production in asthmatic mice through the microRNA-181b/ HMGB1 axis. Int Immunopharmacol 2021;94:107488

59 Wang $X$, Chen J. Long non-coding RNA TUG1 promotes proliferation and migration in PDGF-BB-stimulated HASMCs by regulating miR-216a-3p/SMURF2 axis. BMC Mol Cell Biol 2021:22:56.

60 Zhou H, Long C, Liu P, et al. Long non-coding RNA TUG1 accelerates abnormal growth of airway smooth muscle cells in asthma by targeting the miR-138-5p/E2F3 axis. Exp Ther Med 2021:22:1-9.

61 Zhang $X-Y$, Tang $X-Y$, Li N, et al. Gas5 promotes airway smooth muscle cell proliferation in asthma via controlling miR-10a/BDNF signaling pathway. Life Sci 2018;212:93-101.

62 Keenan CR, Schuliga MJ, Stewart AG. Pro-Inflammatory mediators increase levels of the noncoding RNA GAS5 in airway smooth muscle and epithelial cells. Can J Physiol Pharmacol 2015:93:203-6.

63 Wu D, Gu B, Qian Y, et al. Long non-coding RNA growth arrest specific-5: a potential biomarker for early diagnosis of severe asthma. J Thorac Dis 2020;12:1960-71.

64 Aravamudan B, Thompson MA, Pabelick CM, et al. Mechanisms of BDNF regulation in asthmatic airway smooth muscle. Am J Physiol Lung Cell Mol Physiol 2016:311:L270-9.

$65 \mathrm{Yu}$ X, Zhe Z, Tang B, et al. $\alpha$-Asarone suppresses the proliferation and migration of ASMCs through targeting the IncRNA-PVT1/miR-203a/E2F3 signal pathway in RSVinfected rats. Acta Biochim Biophys Sin 2017;49:598-608.

66 Wei Y, Han B, Dai W, et al. Exposure to ozone impacted Th1/Th2 imbalance of $C^{4+} T$ cells and apoptosis of ASMCs underlying asthmatic progression by activating IncRNA PVT1-miR-15a-5p/miR-29c-3p signaling. Aging 2020;12:25229-55.

$67 \mathrm{Ma} \mathrm{L}$, Zhang Q, Hao J, et al. Lncrna PVT1 exacerbates the inflammation and cell-barrier injury during asthma by regulating miR-149. J Biochem Mol Toxicol 2020;34:e22563.

68 Persson H, Kwon AT, Ramilowski JA, et al. Transcriptome analysis of controlled and therapy-resistant childhood asthma reveals distinct gene expression profiles. J Allergy Clin Immunol 2015;136:638-48 
69 Gao P, Ding Y, Yin B, et al. Long noncoding RNA LINC-PINT retards the abnormal growth of airway smooth muscle cells via regulating the microRNA-26a-5p/PTEN axis in asthma. Int Immunopharmacol 2021;99:107997.

70 Li Q, Lu L, Li X, et al. Long non-coding RNA NKILA alleviates airway inflammation in asthmatic mice by promoting M2 macrophage polarization and inhibiting the NF- $\kappa B$ pathway. Biochem Biophys Res Commun 2021;571:46-52.

71 Li W, Wang X, Sun S, et al. Long non-coding RNA colorectal neoplasia differentially expressed correlates negatively with miR-33a and miR-495 and positively with inflammatory cytokines in asthmatic children. Clin Respir J 2021;15:1175-84.

72 Sun S, Yao M, Yuan L, et al. Long-Chain non-coding RNA n337374 relieves symptoms of respiratory syncytial virus-induced asthma by inhibiting dendritic cell maturation via the CD86 and the ERK pathway. Allergol Immunopathol 2021;49:100-7.

73 Cai X-J, Huang L-H, Zhu Y-K, et al. Lncrna OIP5-AS1 aggravates house dust mite-induced inflammatory responses in human bronchial epithelial cells via the miR-143-3p/HMGB1 axis. Mol Med Rep 2020;22:4509-18.

74 Yu H, Qi N, Zhou Q. Lncrna H19 inhibits proliferation and migration of airway smooth muscle cells induced by PDGF-BB through miR-21/PTEN/Akt axis. J Asthma Allergy $2021 ; 14: 71-80$.

75 Xia L, Wang X, Liu L, et al. Inc-BAZ2B promotes M2 macrophage activation and inflammation in children with asthma through stabilizing BAZ2B pre-mRNA. J Allergy Clin Immunol 2021;147:921-32.
76 Zhang X-Y, Zhang L-X, Tian C-J, et al. Lncrnas BCYRN1 promoted the proliferation and migration of rat airway smooth muscle cells in asthma via upregulating the expression of transient receptor potential 1. Am J Trans/ Res 2016;8:3409-18.

77 Pei W, Zhang Y, Li X, et al. Lncrna AK085865 depletion ameliorates asthmatic airway inflammation by modulating macrophage polarization. Int Immunopharmacol 2020;83:106450.

78 Fan M, Xu J, Xiao Q, et al. Long non-coding RNA TCF7 contributes to the growth and migration of airway smooth muscle cells in asthma through targeting TIMMDC1/Akt axis. Biochem Biophys Res Commun 2019:508:749-55.

79 Akenroye AT, Brunetti T, Romero K, et al. Genome-Wide association study of asthma, total IgE, and lung function in a cohort of Peruvian children. J Allergy Clin Immunol 2021;148:1493-504.

80 Chu C, Chang HY. ChIRP-MS: RNA-directed proteomic discovery. Methods Mol Biol 2018;1861:37-45.

81 Liu Y, Huang Y, Zhang J, et al. TIMMDC1 knockdown inhibits growth and metastasis of gastric cancer cells through metabolic inhibition and AKT/GSK3 $\beta / \beta$-catenin signaling pathway. Int J Biol Sci 2018;14:1256-67.

82 Golovina VA, Platoshyn O, Bailey CL, et al. Upregulated TRP and enhanced capacitative $\mathrm{Ca}(2+)$ entry in human pulmonary artery myocytes during proliferation. Am J Physiol Heart Circ Physiol 2001;280:H746-55. 